\title{
THE REACTIVATED THYMUS *
}

\author{
GEORGE HOWARD HOXIE, M.D. \\ KANSAS CITY, MO.
}

\begin{abstract}
"Persistent thymus" has been a term in the literature, though a term about which much skepticism has gathered. But it is gradually becoming established as a fact that the thymic parenchyma persists throughout life, and that this parenchyma may become reactivated to the extent that its secretion influences the endocrine equilibrium. The causes of such a reactivation are not known. Studies of the histologic picture afforded by such a reactivation are rare; hence the following data from a case that for want of a better term may be called thymic myasthenia.
\end{abstract}

\section{REPORT OF CASE}

History.-G. N., a farmer, first seen at the age of 19, had been suffering for two years from shortness of breath. He had measles as a child; no other diseascs except a headache about three to five times a year since 10 years of age. The patient vomited at the end of each attack. Formerly he was the "fattest" one in the family, but was now thin. Sleep was poor on account of a "stretching of the diaphragm"-evidently a feeling of constriction.

Examination.-The examination showed a short but well-proportioned young man, with no external evidence of disease. The stomach was dilated, reaching to the navel. Diastolic blood pressure was 95, systolic 130 . The urine was negative, except for increased indican. The white blood cells numbered 13,600 , polymorphonuclear cells 65 per cent., and large lymphocytes 33. Gastric lavage and intestinal cleansing had no effect on the subjective symptoms. Four ounces of sugar caused no glycosuria. Epinephrin (adrenalin), 1 c.c. of $1: 3,200$ solution, raised the temperature in twenty minutes from 98.6 to $99 \mathrm{~F}$., the pulse remaining at 84 . The temperature was labile and easily raised by emotional and physical excitement. The condition was not affected by the administration of thyroid extract 1 grain three times a day for one month.

Examination by surgeon (Dr. Binnie) was negative; by neurologist ( $\mathrm{Dr}$. Skoog), negative; roentgenogram of spine (Dr. Skinner), negative.

Findings.-The only important physical finding was increased submanubrial dulness, the outlines of which are shown in the accompanying photograph (Fig. 1). The roentgenogram of the chest (Fig. 2) shows an enlarged shadow in this area.

The manubrium was resected (Dr. Binnie) and some pieces of thymus removed. The microscopic study of these (Figs. 3 and 4 ) shows the epithelialization described by Matti and Klose as characteristic of the reactivation of the adult thymus.

624 Rialto Building.

\footnotetext{
* Submitted for publication Oct. 16, 1916.
} 


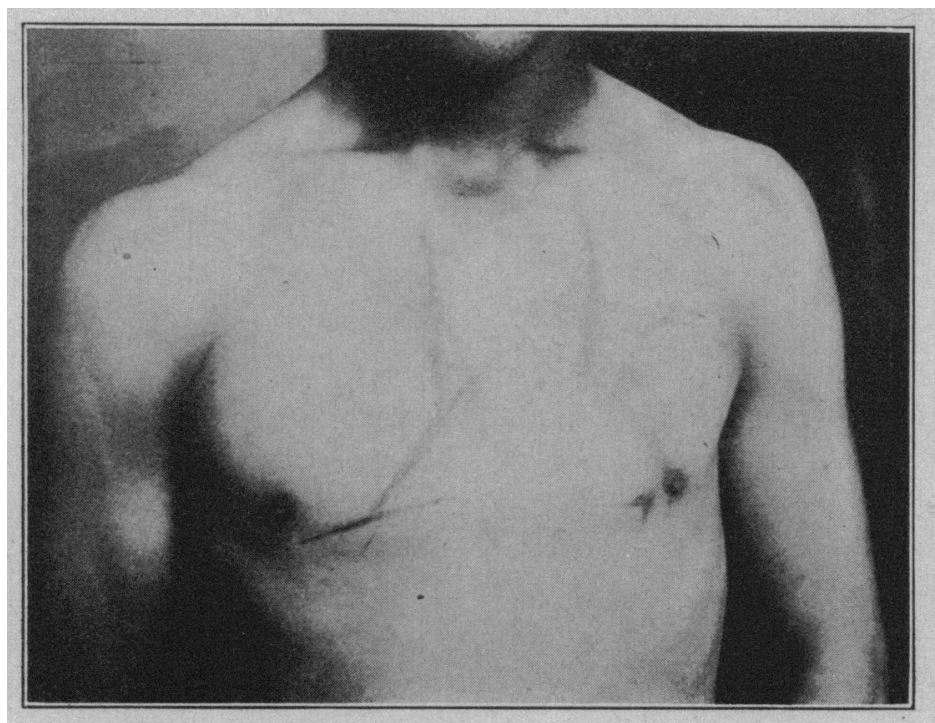

Fig. 1.-Showing the area of thymus dulness.

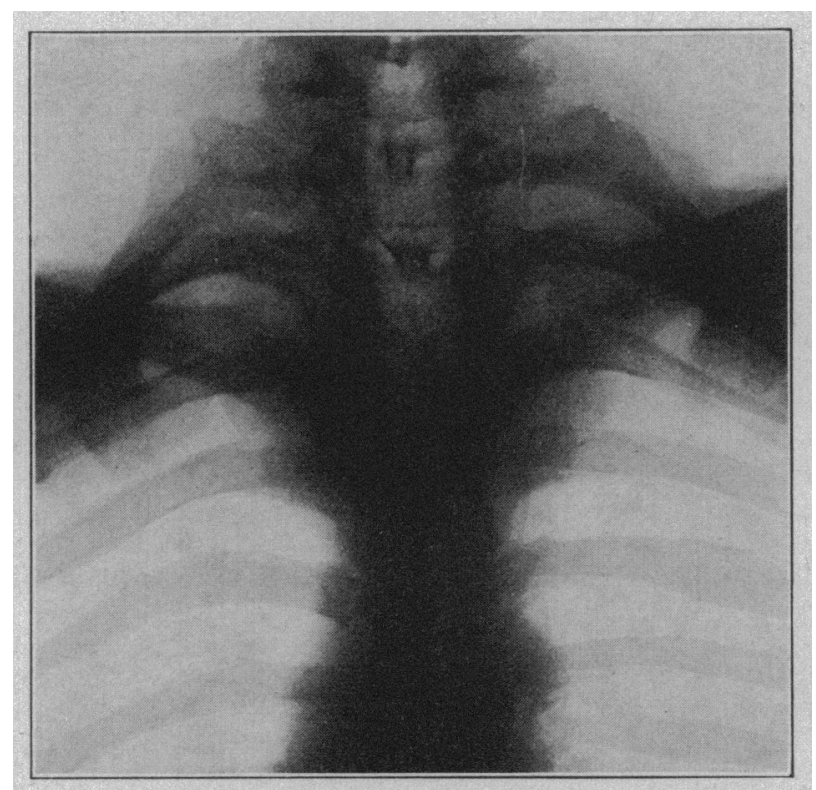

Fig. 2.--Roentgenogram slowing the increased shadow in the thymic area. 


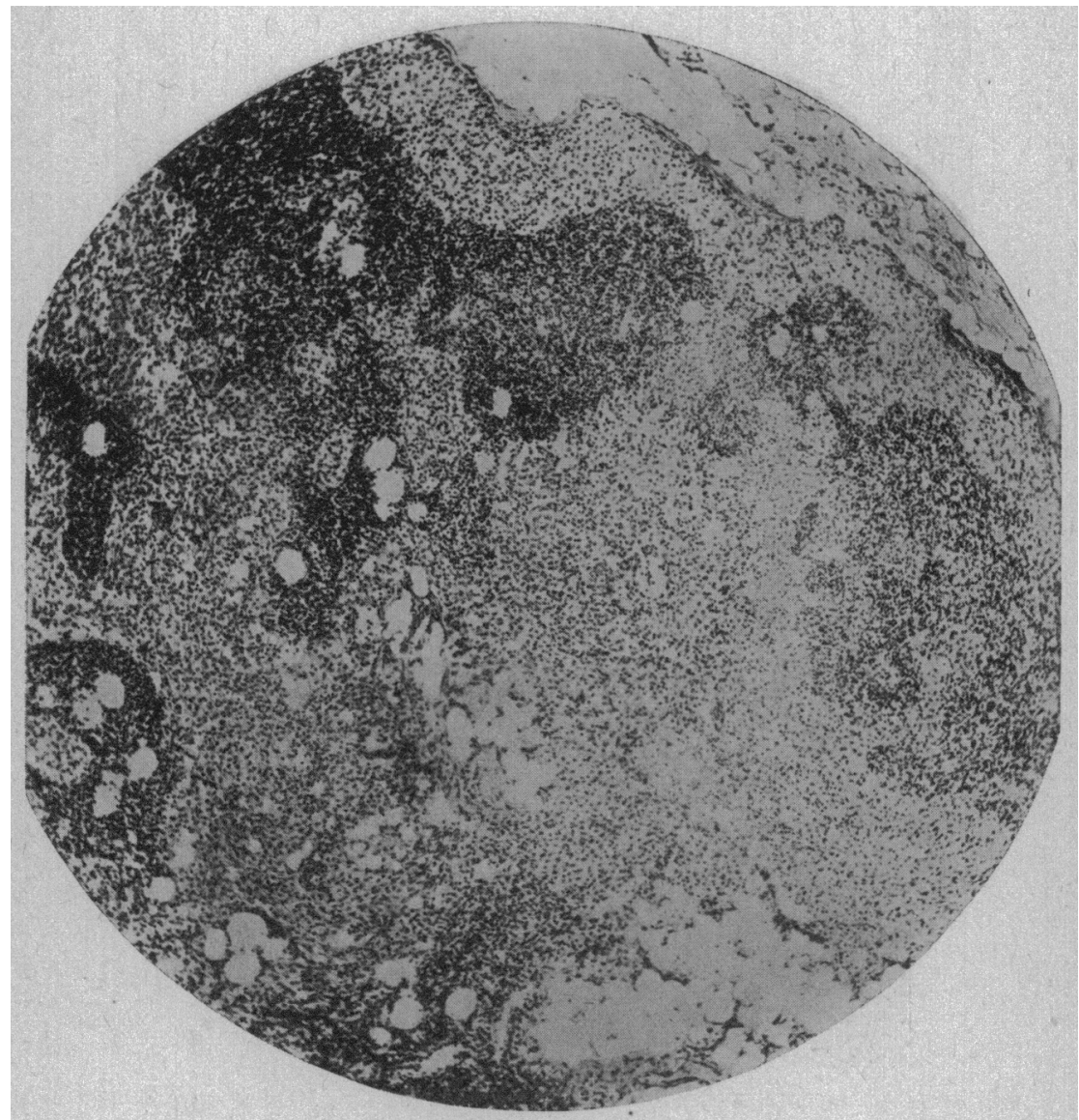

Fig. 3.-Section of thymic tissue under low power. Note the increase in the light areas, the Hassall corpuscles and the inroads of the vacuolization. 


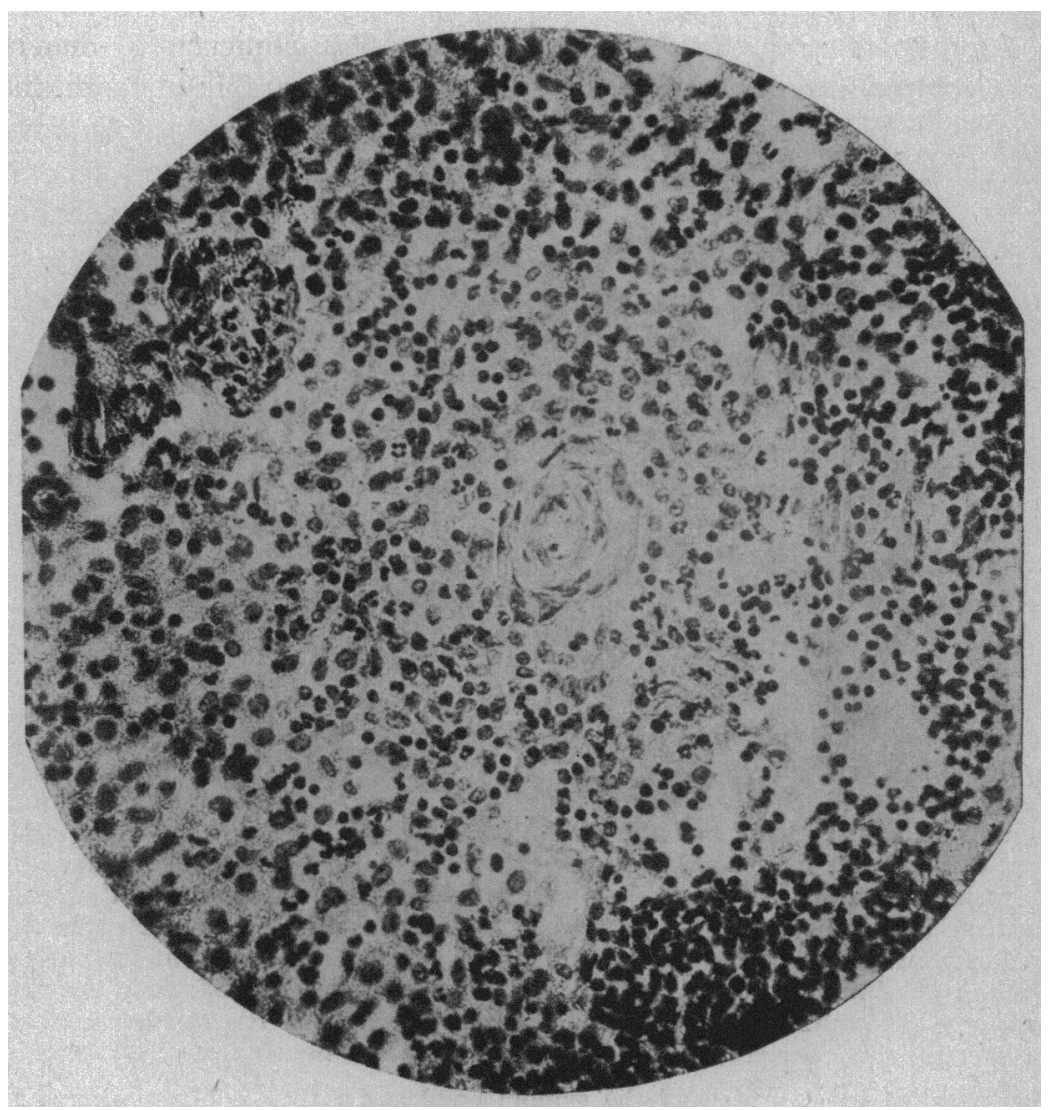

Fig. 4.-Higher magnification of the central portion of the low power field shown in Figure 3. 